\title{
A 23 years follow-up study identifies GLUT1 deficiency syndrome initially diagnosed as complicated hereditary spastic paraplegia
}

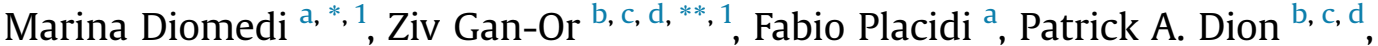

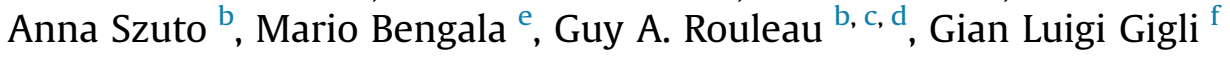 \\ ${ }^{a}$ Neurological Clinic, Department of Systems Medicine, Tor Vergata University, Rome, Italy \\ ${ }^{\mathrm{b}}$ Montreal Neurological Institute, McGill University, Montreal, Quebec, Canada \\ ${ }^{\mathrm{c}}$ Departments of Human Genetics, McGill University, Montreal, Quebec, Canada \\ d Department of Neurology \& Neurosurgery, McGill University, Montreal, Quebec, Canada \\ e Medical Genetic Laboratories, Tor Vergata University Hospital, Rome, Italy \\ ${ }^{\mathrm{f}}$ Neurology, Department of Experimental and Clinical Medical Sciences, University of Udine Medical School and Department of Neurosciences, “S. Maria \\ della Misericordia" University Hospital, Udine, Italy
}

\section{A R T I C L E I N F O}

\section{Article history:}

Received 22 July 2016

Received in revised form

5 September 2016

Accepted 1 October 2016

Available online 8 October 2016

\section{Keywords:}

Epilepsy

Spasticity

Hereditary spastic paraplegia

GLUT1 deficiency syndrome

SLC2A1

\begin{abstract}
A B S T R A C T
Glucose transporter 1 (GLUT1) deficiency syndrome (GLUT1DS) was initially described in the early 90s as a sporadic clinical condition, characterized by seizures, motor and intellectual impairment with variable clinical presentation, and without a known genetic cause. Although causative mutations in SLC2A1 were later identified and much more is known about the disease, it still remains largely underdiagnosed. In the current study, a previously described Italian family was re-analyzed using whole exome sequencing and clinically re-evaluated. Affected individuals presented with spastic paraplegia as a predominant symptom, with epilepsy and intellectual disability, inherited as an autosomal dominant trait with variable clinical presentation. While a novel variant of hereditary spastic paraplegia (HSP) was initially hypothesized in this family, previous linkage studies of known HSP genes did not identify the genetic cause. Exome-sequencing study identified a p.Arg126Cys mutation in the SLC2A1 gene, encoding GLUT1, which segregated with the affected members of the family. The diagnosis of GLUT1DS was further confirmed by cerebrospinal fluid analysis, and treatment was started with good initial response. The description of this large family provides further clinical information on this rare disease. It also offers an example of how GLUT1DS can be challenging to diagnose, and emphasizes the importance of lumbar puncture in the workflow of similar syndromes. Finally, it suggests that analysis of SLC2A1 should be considered in the diagnostic work up of HSP, especially if it is associated with epilepsy.
\end{abstract}

๑๐ 2016 Elsevier Masson SAS. All rights reserved.

\section{Introduction}

More than two decades ago, Gigli et al. (Gigli et al., 1993) described an Italian family affected with autosomal dominant spastic paraplegia, epilepsy and intellectual disability. Gait disturbance was the predominant symptom, characterized in all subjects

\footnotetext{
* Corresponding author. Neurological Clinic, University of Rome Tor Vergata, Viale Oxford, 81, 00133 Rome, Italy.

** Corresponding author. Montreal Neurological Institute, The Department of Human Genetics, McGill University, 1033 Pine Avenue, West, Ludmer Pavilion, Room 327, Montreal, QC, H3A 1A1, Canada.

E-mail addresses: marina.diomedi@uniroma2.it (M. Diomedi), ziv.gan-or@mail. mcgill.ca (Z. Gan-Or).

1 These authors contributed equally to the manuscript.
}

by weakness, spasticity and hyperreflexia of lower limbs. A new form of autosomal dominant, complicated hereditary spastic paraplegia (HSP) with incomplete penetrance and variable clinical presentation was hypothesized. HSP can be pure, with only few additional symptoms, or complicated with various additional neurological symptoms, including epilepsy and/or intellectual disability as previously described (Salinas et al., 2008). At the time of the initial report, the family pedigree included four generations with affected individuals (generations I-IV, Fig. 1A). In a follow-up genetic study, markers around 8 known autosomal dominant HSP causing genes/loci were analyzed (Lo Nigro et al., 2003). However, none of these loci was associated with the disease, suggesting that another genetic cause was involved.

Herein, we report the 23-year follow up of the family members, 


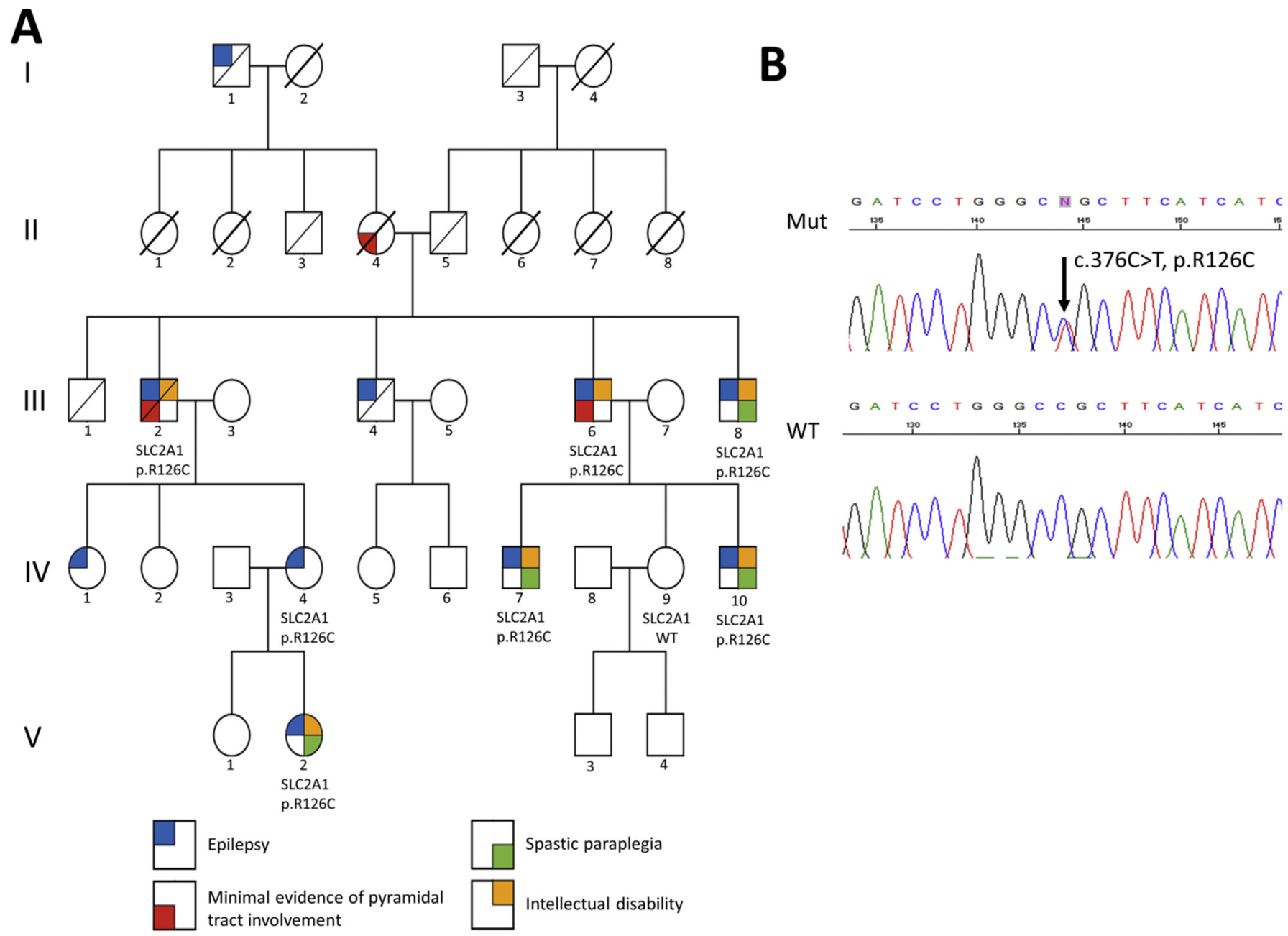

Fig. 1. Pedigree of the family and the SLC2A1 p.Arg126Cys mutation.

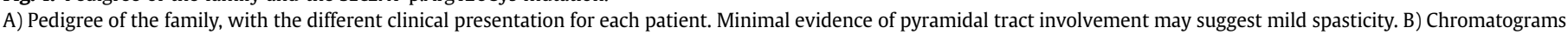

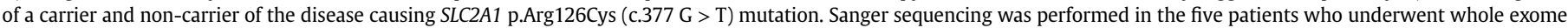
sequencing, and in additional two patients and in one unaffected individual.

now expended to five generations, and the results of a new genetic study revealing glucose transporter 1 (GLUT1) deficiency syndrome (GLUT1DS, MIM \#606777), rather than the hypothesized HSP.

\section{Patients and methods}

\subsection{Clinical report}

A comprehensive description of the patients from generations I-IV was previously reported (Gigli et al., 1993). Spastic paraplegia with gait difficulties were the predominant symptoms; for example, in patient III-8, gait disturbances started at the age of 10 years and only 13 years later, absence with several tonic-clonic seizures were reported. For this reason, a complicated form of HSP was hypothesized, with autosomal dominant mode of inheritance. At the time of the first description, epilepsy was present in seven of the members of the II and III generations for whom we had information. The most frequent electroencephalogram (EEG) alterations were consisted of generalized spike-and-wave complexes with frequency of $3 \mathrm{c} / \mathrm{s}$. High-voltage spike and polyspike-wave complexes with a prevalence on the temporal region with tendency to diffusion were observed in individual IV-1. Twenty-three years later, the family was contacted again to regain follow-up and provide diagnosis and treatment. A summary of the clinical presentation is reported in Table 1.

An updated pedigree is shown in Fig. 1A. To date, gait disturbance remained the predominant symptom, characterized in some members by minimal signs of pyramidal tract involvement (hypertonia in lower limbs, incomplete bilateral Babinski sign, increase in central motor evoked potentials conduction time). All subjects who were examined had weakness, clear spasticity and hyperreflexia of the lower limbs. However, even patients with a severe motor involvement since childhood (IV-7, IV-10) have maintained their autonomy in all daily actions, and were able to perform sport activities, although with some expected difficulties. Dysarthria, characterized by lack of fluency, was present in some members since childhood (IV-7, IV-10). No signs of dystonia or more complex movement disorders were present in any of the family members. During the years after the initial description, patients suffering from epilepsy showed a fluctuating clinical and EEG picture. Most of them presented with electro-clinical features characteristic of generalized epilepsy, although atypical paroxysmal slow waves discharges were also observed. All epileptic patients were under anticonvulsant monotherapy with a fairly good control of seizures. Of the $\mathrm{V}$ generation, which we describe here for the first time, an eight years old female subject (V-2) is affected by a gait disturbance 
Table 1

Summary of clinical findings.

\begin{tabular}{|c|c|c|c|c|c|c|c|}
\hline Patient & Sex & $\begin{array}{l}\text { Spastic paraplegia } \\
\text { (age at onset) }\end{array}$ & $\begin{array}{l}\text { Intellectual disability } \\
\text { (age at onset) }\end{array}$ & $\begin{array}{l}\text { Epilepsy (age } \\
\text { at onset) }\end{array}$ & EEG & AEDs & Other symptoms \\
\hline$I-1^{a}$ & $\mathrm{M}$ & Not examined & Not examined & undetermined & - & - & - \\
\hline $\mathrm{II}-4^{\mathrm{a}}$ & $\mathrm{F}$ & $\begin{array}{l}\text { Undetermined } \\
\text { (minimal signs) }\end{array}$ & - & - & - & - & - \\
\hline III- $2^{\mathrm{a}}$ & M & $\begin{array}{l}\text { Undetermined } \\
\text { (minimal signs) }\end{array}$ & Undetermined (mild) & 20 years & $\begin{array}{l}\text { generalized spike and } 3 \mathrm{c} / \mathrm{s} \text { wave } \\
\text { discharge complexes }\end{array}$ & - & - \\
\hline III- $4^{\mathrm{a}}$ & M & Not examined & Not examined & childhood & & - & - \\
\hline III-6 & M & $\begin{array}{l}\text { Undetermined } \\
\text { (minimal signs) }\end{array}$ & Undetermined (mild) & 7 years & $\begin{array}{l}\text { generalized bursts of } 3 \mathrm{c} / \mathrm{s} \text { spike and } \\
\text { wave discharges }\end{array}$ & Valproate $500 \mathrm{mg}$ bid & - \\
\hline III-8 & M & 10 years & Undetermined (mild) & 23 years & $\begin{array}{l}\text { generalized bursts of } 3 \mathrm{c} / \mathrm{s} \text { spike and } \\
\text { wave discharges }\end{array}$ & Valproate $500 \mathrm{mg}$ bid & - \\
\hline IV-1 & $\mathrm{F}$ & - & - & childhood & $\begin{array}{l}\text { high-voltage spike and polyspike } \\
\text {-wave complexes prevalent on the } \\
\text { temporal region }\end{array}$ & Levetiracetam $500 \mathrm{mg}$ bid & - \\
\hline IV-4 & $\mathrm{F}$ & - & $\begin{array}{l}\text { Adulthood } \\
\text { (moderate) }\end{array}$ & 18 years & normal & none & - \\
\hline IV-7 & M & 3 years & $\begin{array}{l}\text { early childhood } \\
\text { (moderate) }\end{array}$ & 3 years & $\begin{array}{l}\text { generalized bursts of } 3 \mathrm{c} / \mathrm{s} \text { spike and } \\
\text { wave discharges }\end{array}$ & none & Hypertension \\
\hline IV-10 & M & 4 years & $\begin{array}{l}\text { early childhood } \\
\text { (moderate) }\end{array}$ & 4 years & $\begin{array}{l}\text { generalized bursts of } 3 \mathrm{c} / \mathrm{s} \text { spike and } \\
\text { wave discharges }\end{array}$ & Levetiracetam $500 \mathrm{mg}$ bid & $\begin{array}{l}\text { Hypertension, chronic } \\
\text { renal insufficiency }\end{array}$ \\
\hline $\mathrm{V}-2$ & $\mathrm{~F}$ & Infancy & Infancy (moderate) & Infancy & $\begin{array}{l}\text { sharp waves, generalized spikes } \\
\text { and/or spike and wave complexes, } \\
\text { predominant over the right fronto- } \\
\text { temporo-central regions. }\end{array}$ & $\begin{array}{l}\text { valproate } 250 \mathrm{mg} \text { bid and } \\
\text { lamotrigine } 25 \mathrm{mg} \text { bid }\end{array}$ & - \\
\hline
\end{tabular}

EEG, electroencephalography; AED, ongoing anti-epileptic drug therapy; M, male; F, female

a Dead at current reevaluation.

with lower limbs spasticity, moderate intellectual deficit and poor language skills with slowed fluency. Absence and generalized tonic-clonic seizures are reported with a monthly frequency of one or two episodes, despite of antiepileptic treatment. Her EEG shows the presence of sharp waves, generalized spikes and/or spike-andwave complexes, predominant over the right fronto-temporocentral regions. At a clinical evaluation, the severity of intellectual disability appears mild to moderate in all patients.

\subsection{Methods}

Written informed consent was obtained from all participants, and study protocols were approved by the respective IRBs. DNA from five patients was produced using a standard salting out protocol and was sent for whole exome sequencing, performed and analyzed in the Montreal Neurological Institute, Montreal, Canada. Since the disease is autosomal dominant, we filtered-in only rare variants that are not found in the following publicly available databases: the 1000 genome project, the Exome Variant Server (EVS) NHLBI GO Exome Sequencing Project (ESP), and dbSNP132. We further filtered-in only nonsynonymous, frameshift and stop-gain variants that segregated with all the five samples. All nomenclature is based on the hg19 assembly.

To estimate the potential effects of the mutation, we used the online prediction and conservation tools SIFT, PolyPhen-2, MutationTaster, PhyloP and GERP ++ . In order to validate and examine the segregation of the candidate mutations with the disease, DNA from eight individuals was analyzed using Sanger sequencing: the five patients whose samples were sent for whole exome sequencing, two additional affected individuals, and one unaffected individual. DNA was amplified using the specific forward primer $5^{\prime}$ - CCTGCCCAGGGAGTCCCAG and reverse primer 5' - GCTGGGCACAGATCCGAGAG, following by Sanger sequencing (Applied Biosystem's 3730xl DNA Analyzer technology).

\section{Results}

The average coverage of the exome of the five sequenced patients was $112.8 \mathrm{X}$, with more than $98 \%$ of nucleotides covered by at least $10 \mathrm{X}$, and more than $92 \%$ by at least $20 \mathrm{X}$ in all samples. After filtration and segregation analysis, a mutation in the SLC2A1 gene (NM_006516), p.Arg126Cys (c.377 G > T), known to cause GLUT1DS, was identified (Fig. 1B). The mutation was further validated using Sanger sequencing in the five initial patients and in additional three samples, including one un-affected individual who was confirmed as a non-carrier of the mutation (Fig. $1 \mathrm{~A}$ and $\mathrm{B}$ ).

Two subjects (IV-7, IV-10) underwent video-EEG monitoring, brain MRI and lumbar puncture for CSF analysis. The EEGs showed subclinical generalized spike and wave complex discharges, similar to those previously described. Food intake lead to an improvement of the EEG with a dramatic reduction of the epileptiform abnormalities in a new recording performed one hour after meal (Fig. 2). Brain MRI was unremarkable. Cerebrospinal fluid analysis revealed a low glucose concentration $(34.00 \mathrm{mg} / \mathrm{dl}$ in both patients; normal values $45-76 \mathrm{mg} / \mathrm{dl}$ ) and reduced glucose CSF/serum ratio (38.2\% in IV-7 and 39.08\% in IV-10; normal value $>45 \%$ ), in the presence of normal lactate level.

Following the diagnosis, all affected subjects received genetic counseling to inform them on the diagnosis and future implications, including future genetic counseling and tests that will be necessary if the family wishes to further expand. The affected individuals are currently receiving an appropriate ketogenic diet with an improvement of epileptic and gait manifestations, and with a significant reduction of fatigue and weakness.

\section{Discussion}

When this family was initially described (Gigli et al., 1993), GLUT1DS had been just reported by De Vivo et al. in two patients with infantile seizures, delayed development, and acquired microcephaly, without spastic paraplegia (De Vivo et al., 1991). The phenotype had broadened only over the following years to include spasticity among the reported features (developmental encephalopathy with infantile seizures, acquired microcephaly, paroxysmal events including confusion, lethargy, hemiparesis, ataxia, sleep disturbances, and headaches) (Wang et al., 2005). Furthermore, it is 

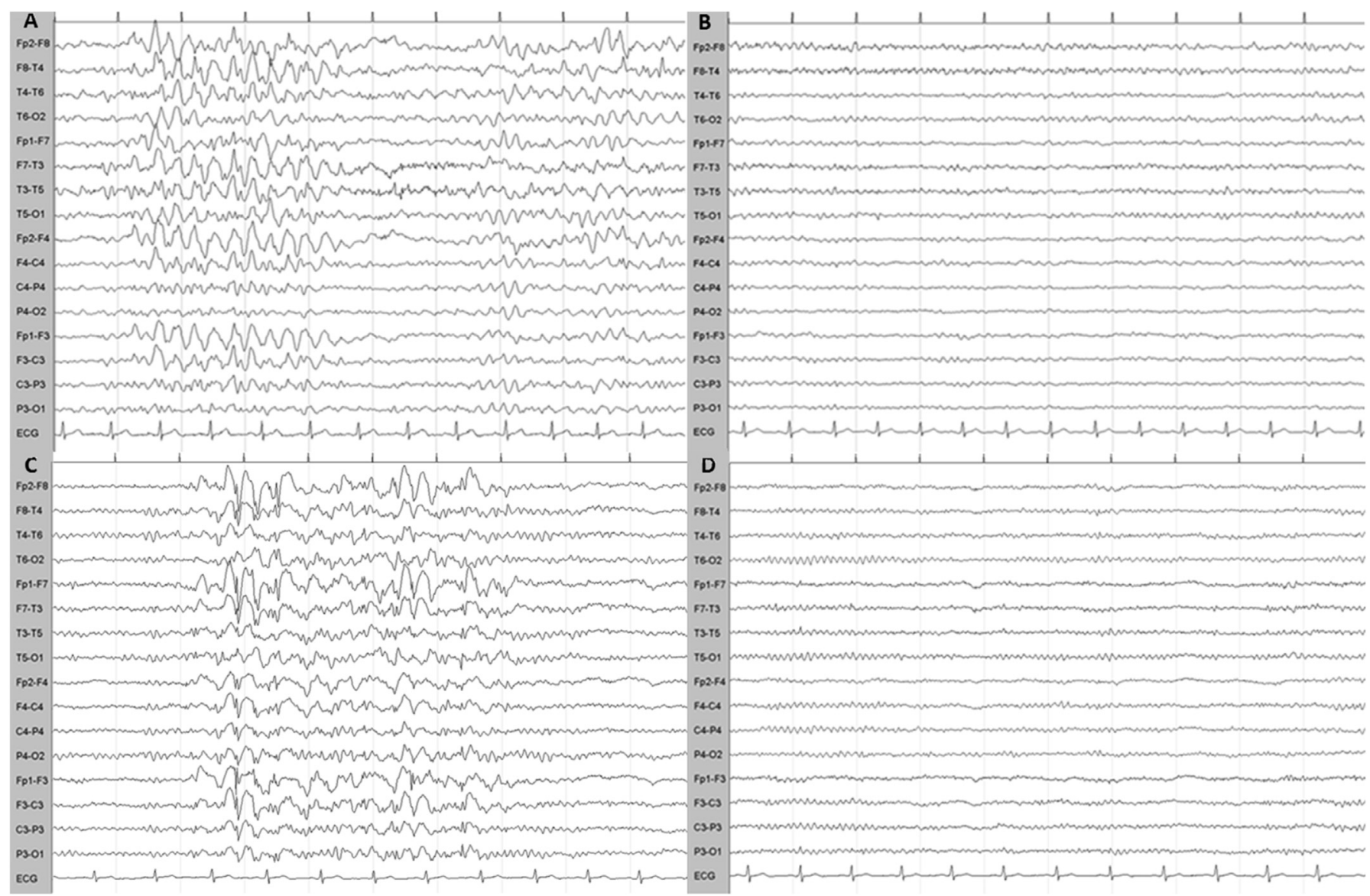

Fig. 2. EEG recording in two patients with GLUT1: the effect of food intake.

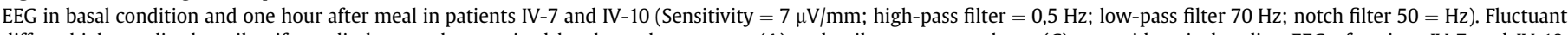

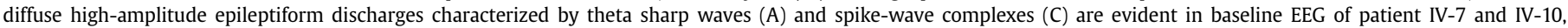
respectively. Food intake provoked the dramatic disappearance of paroxysmal activity in both cases (B, D).

known that complicated HSP can include epilepsy and intellectual disability. Therefore, at the time of the first observation, the attention of the treating clinicians was mainly drawn to the predominant motor deficit of the patients, rather than to their less prominent and fluctuating epileptic manifestations. In the light of the current knowledge, the diagnosis should have been easily made in the following years. However, the new study was carried out only recently, allowing a long follow up in different generations. This is in line with a recent study suggesting that GLUT1DS is underdiagnosed, and its frequency in certain populations may reach to about 1:83,000-1:90,000 (Coman et al., 2006; Larsen et al., 2015).

The classical phenotype of GLUT1DS is characterized by infantile seizures (resistant to traditional seizure medications), developmental delay, acquired microcephaly and complex movement disorders consisting of ataxia, dystonia and spasticity, more often paroxystic. The clinical spectrum observed at the time of the first publication was dominated by spastic paraplegia, a mild to moderate intellectual disability and by rather well controlled epilepsy. Pyramidal tract involvement associated with spastic paraplegia was one of the main clinical manifestations in six members of three generations. Of note, gait disturbances and movement disorders are frequent GLUT1DS, resulting from chronic or intermittent pyramidal, cerebellar and extrapyramidal circuit dysfunction. It was reported that $89 \%$ of patients with GLUT1DS have a gait disturbance consisting of dyskinesia, ataxia, chorea and spasticity (Pons et al., 2010). The presence of spastic paraplegia which is not paroxysmal, in absence of ataxia, is uncommon. Even in patients who carried the same mutation as in our family (c.376 C $>\mathrm{T}$, p.Arg126Cys), pyramidal signs were rarely reported. Persistent spastic paraplegia was associated with ataxia in one Italian woman and with paroxysmal choreoathetosis in Australian twin brothers (Weber et al., 2011; Zorzi et al., 2008). Intellectual disability was mild to moderate in severity and was not associated with microcephaly, which is a typical sign of GLUT1DS. Unlike the spectrum of focal and multifocal seizure types reported in the literature for GLUT1DS, the patients described here presented, especially in childhood, with a quite monomorphic clinical pattern compatible with a diagnosis of generalized epilepsy (Pong et al., 2012). Differences in epileptiform features appear even among patients with GLUT1DS harboring the SLC2A1 p.Arg126Cys mutation, in which typical absence seizures or myoclonic absences are the most prevalent seizure type reported (Gokben et al., 2011; Suls et al., 2009; Zorzi et al., 2008).

Little is known about the disease course. A recent study (Leen et al., 2014) reported a systematic literature review and a cohort study, including GLUT1DS patients aged 18 years and older, and described the disease course from infancy into adulthood. These patients had complex phenotype, in which the pyramidal involvement mainly presented as ataxia and paroxysmal dyskinesia, and the effect of ketogenic diet on these symptoms remained unclear. The authors reported a reduction of epileptic manifestations and an appearance or worsening of paroxysmal movement disorders during adolescence, while cognitive functions appeared to be stabile throughout life (Leen et al., 2014). In the family described 
herein, even without receiving ketogenic diet, clinical symptoms seemed to not deteriorate during follow-up. This was in agreement with a longitudinal study of 13 patients that demonstrated that different outcome measures did not significantly change over time (Alter et al., 2015). Paroxysmal movement disorder was not reported nor in infancy neither in adulthood. Furthermore, epileptic manifestations, gait disturbances and cognitive performances, remained quite stable in adulthood. This observation is in agreement with the previously reported milder phenotype in familial cases compared to sporadic forms (De Giorgis et al., 2015). Nevertheless, the long follow-up allowed us to evaluate several generations along many years: we observed an increase in severity and an earlier clinical onset in the affected members of the latest generations compared to the antecedent ones, suggesting an anticipation effect. Anticipation was previously reported in a family with a similar mutation, p.Arg126His, and it was suggested that if a mother is affected, it may potentiate the disease onset of her fetus, which may explain the observed anticipation (Brockmann et al., 2001). However, evidence for anticipation in children to affected fathers was also reported, as the two children of an affected father had moderate intellectual disability, ataxia and pyramidal signs, while the father had only mild intellectual disability and no motor symptoms (Klepper et al., 2001).

Our report further emphasizes the need for consideration of GLUT1DS in cases of familial epilepsy and variable manifestations involving motor and cognitive functions. The description of this large family provides example of how GLUT1DS should be considered in the diagnostic work up of autosomal dominant spastic paraplegia associated with epilepsy, for an early and accurate diagnosis. Diagnosis at birth of these patients could lead to an early therapeutic intervention with an appropriate ketogenic diet as the best course of treatment. Even in adults, who were diagnosed late, ketogenic diet may have disease-modifying effects reducing epileptic and other neurological manifestations. Such early intervention may be effective not only for controlling epilepsy, but also for reducing the burden of motor symptoms, as was previously suggested (Alter et al., 2015). Finally, the current report emphasizes the need for consideration lumbar puncture in the workup of neurological disorders without a diagnosis, which may lead to earlier diagnosis.

\section{Acknowledgements}

We thank the patients and their family for their participation. The study was funded by the Canadian Institute for Health Research (CIHR) (RN127580-260005). ZGO is supported by a postdoctoral fellowship from the Canadian Institutes for Health Research (CIHR). GAR holds a Canada Research Chair in Genetics of the Nervous System and the Wilder Penfield Chair in Neurosciences. We thank Helene Catoire, Pascale Hince, and Cathy Mirarchi for their assistance.

\section{References}

Alter, A.S., Engelstad, K., Hinton, V.J., Montes, J., Pearson, T.S., Akman, C.I., De Vivo, D.C., 2015. Long-term clinical course of Glut1 deficiency syndrome. J. Child. Neurol. 30 (2), 160-169.

Brockmann, K., Wang, D., Korenke, C.G., von Moers, A., Ho, Y.Y., Pascual, J.M., Kuang, K., Yang, H., Ma, L., Kranz-Eble, P., Fischbarg, J., Hanefeld, F., De Vivo, D.C., 2001. Autosomal dominant glut-1 deficiency syndrome and familial epilepsy. Ann. Neurol. 50 (4), 476-485.

Coman, D.J., Sinclair, K.G., Burke, C.J., Appleton, D.B., Pelekanos, J.T., O'Neil, C.M., Wallace, G.B., Bowling, F.G., Wang, D., De Vivo, D.C., McGill, J.J., 2006. Seizures, ataxia, developmental delay and the general paediatrician: glucose transporter 1 deficiency syndrome. J. Paediatr. Child. Health 42 (5), 263-267.

De Giorgis, V., Teutonico, F., Cereda, C., Balottin, U., Bianchi, M., Giordano, L., Olivotto, S., Ragona, F., Tagliabue, A., Zorzi, G., Nardocci, N., Veggiotti, P., 2015. Sporadic and familial glut1ds Italian patients: a wide clinical variability. Seizure 24, 28-32.

De Vivo, D.C., Trifiletti, R.R., Jacobson, R.I., Ronen, G.M., Behmand, R.A., Harik, S.I., 1991. Defective glucose transport across the blood-brain barrier as a cause of persistent hypoglycorrhachia, seizures, and developmental delay. N. Engl. J. Med. 325 (10), 703-709.

Gigli, G.L., Diomedi, M., Bernardi, G., Placidi, F., Marciani, M.G., Calia, E., Maschio, M.C., Neri, G., 1993. Spastic paraplegia, epilepsy, and mental retardation in several members of a family: a novel genetic disorder. Am. J. Med. Genet. 45 (6), 711-716.

Gokben, S., Yilmaz, S., Klepper, J., Serdaroglu, G., Tekgul, H., 2011. Video/EEG recording of myoclonic absences in GLUT1 deficiency syndrome with a hot-spot R126C mutation in the SLC2A1 gene. Epilepsy Behav. 21 (2), 200-202.

Klepper, J., Willemsen, M., Verrips, A., Guertsen, E., Herrmann, R., Kutzick, C. Florcken, A., Voit, T., 2001. Autosomal dominant transmission of GLUT1 deficiency. Hum. Mol. Genet. 10 (1), 63-68.

Larsen, J., Johannesen, K.M., Ek, J., Tang, S., Marini, C., Blichfeldt, S., Kibaek, M., von Spiczak, S., Weckhuysen, S., Frangu, M., Neubauer, B.A., Uldall, P., Striano, P., Zara, F., Consortium, M.A.E.w.g.o.E.R., Kleiss, R., Simpson, M., Muhle, H., Nikanorova, M., Jepsen, B., Tommerup, N., Stephani, U., Guerrini, R., Duno, M., Hjalgrim, H., Pal, D., Helbig, I., Moller, R.S., 2015. The role of SLC2A1 mutations in myoclonic astatic epilepsy and absence epilepsy, and the estimated frequency of GLUT1 deficiency syndrome. Epilepsia 56 (12), e203-208.

Leen, W.G., Taher, M., Verbeek, M.M., Kamsteeg, E.J., van de Warrenburg, B.P., Willemsen, M.A., 2014. GLUT1 deficiency syndrome into adulthood: a follow-up study. J. Neurol. 261 (3), 589-599.

Lo Nigro, C., Cusano, R., Gigli, G.L., Forabosco, P., Valente, M., Ravazzolo, R., Diomedi, M., Seri, M., 2003. Genetic heterogeneity in inherited spastic paraplegia associated with epilepsy. Am. J. Med. Genet. A 117A (2), 116-121.

Pong, A.W., Geary, B.R., Engelstad, K.M., Natarajan, A., Yang, H., De Vivo, D.C., 2012. Glucose transporter type I deficiency syndrome: epilepsy phenotypes and outcomes. Epilepsia 53 (9), 1503-1510.

Pons, R., Collins, A., Rotstein, M., Engelstad, K., De Vivo, D.C., 2010. The spectrum of movement disorders in Glut-1 deficiency. Mov. Disord. 25 (3), 275-281.

Salinas, S., Proukakis, C., Crosby, A., Warner, T.T., 2008. Hereditary spastic paraplegia: clinical features and pathogenetic mechanisms. Lancet Neurol. 7 (12), 1127-1138.

Suls, A Mullen, S.A. Weber, YG. Verhaert, K, Ceulemans, B., Guerrini, R. Wuttke, T.V., Salvo-Vargas, A., Deprez, L., Claes, L.R., Jordanova, A., Berkovic, S.F., Lerche, H., De Jonghe, P., Scheffer, I.E., 2009. Early-onset absence epilepsy caused by mutations in the glucose transporter GLUT1. Ann. Neurol. 66 (3), 415-419.

Wang, D., Pascual, J.M., Yang, H., Engelstad, K., Jhung, S., Sun, R.P., De Vivo, D.C., 2005. Glut-1 deficiency syndrome: clinical, genetic, and therapeutic aspects Ann. Neurol. 57 (1), 111-118.

Weber, Y.G., Kamm, C., Suls, A., Kempfle, J., Kotschet, K., Schule, R., Wuttke, T.V., Maljevic, S., Liebrich, J., Gasser, T., Ludolph, A.C., Van Paesschen, W., Schols, L., De Jonghe, P., Auburger, G., Lerche, H., 2011. Paroxysmal choreoathetosis/spasticity (DYT9) is caused by a GLUT1 defect. Neurology 77 (10), 959-964.

Zorzi, G., Castellotti, B., Zibordi, F., Gellera, C., Nardocci, N., 2008. Paroxysmal movement disorders in GLUT1 deficiency syndrome. Neurology 71 (2) 146-148. 